\title{
Mobile Collection and Dissemination of Seniors' Skills
}

\author{
http://dx.doi.org/10.3991/ijac.v8i3.4842 \\ Anne-Dominique Salamin, Leyun Xia \\ HES-SO/Institute of Information Systems, Sierre, Switzerland
}

\begin{abstract}
Mocodis is a web application facilitating the transfer of skills between senior and junior associates. It can be used in companies, institutions to capitalize on the experience of older employees, or can be used to train employees top down. Mocodis automatically generates dynamic microcourses combining text, audio and video resources, and uses an algorithm to analyze user satisfaction to produce better courses at the next request.
\end{abstract}

Index Terms-e-learning, company, senior, skills, transfer.

\section{INTRODUCTION}

Worldwide, the population aged 60 and older, is growing faster than any other age group. The $60+$ population, at 605 million today, will almost double by 2025 , to 1.2 billion. By 2050, it will reach 2 billion-marking the first time in history when people aged 60 and over will outnumber children aged 14 and under. ${ }^{1}$

This aging trend is most pronounced in Europe, where, by 2025 , eight out of 10 "older" people - that is, the percentage of people above the age of 60 - in the population, it will rank among the countries worldwide with at least 10 million people. ${ }^{2}$

By 2050 , an estimated $35 \%$ of the European population will be over the age of 60 , compared to $20 \%$ today. The European working-age population will fall, as its ageing population grows. By 2050, the number of people in working age (defined as 15 to 64-years-old) in Europe will plummet by approximately 130 million. (ibid)

The recent report on the Taskforce Employment 13 set clear priorities for further action and called upon Member states and social partners for defining a comprehensive active ageing policy centered on: "Older workers must not be perceived as just another vulnerable group meriting special attention, but as a core component of the labor supply and a key factor for the sustainable development of the European Union."

Nowadays, companies, associations, NGO evaluations are not only targeted on financial assets, but also on intangible assets: human capital orientation. This change of vision led to develop the concept of human capital.

1 “An Aging World 2001, U.S. Department of Commerce, UN Department of Public Information, DP/2264, March 2002" quoted on http://www.thematuremarket.com/SeniorStrategic/ageing_population_eu ropean facts-6204-5.html

2 Population Division of the Department of Economic and Social Affairs of the UTWENTEed Nations Secretariat, World Population Prospects, quoted in

http://www.thematuremarket.com/SeniorStrategic/ageing population eu ropean facts-6204-5.html
These objectives could be achieved in different ways:

1. Favor senior recruitment

2. Maintain near-retirement collaborators in their workplace

3. Capitalize the seniors' competencies

Mobile Collection and Dissemination of Seniors' Skills system (MOCODIS) focuses on the third point.

\section{SENIORS' SKILLS}

The term "senior", as used in the MOCODIS project, entails "elder workers, integrated in a company or association, and retiring within 5 years".

The term "worker" refers to distinct targets addressed in MOCODIS :

- employees of public or private companies

- volunteers in NGO and associations

Seniors are indeed the trustees of knowledge and multiple competencies. Seniors can bestow their expertise in many fields, firm background, niche skills, maturity, calmness, global vision, implementation, wisdom etc.

Unfortunately, these competencies are wasted for the firm or the association once the seniors have definitely left, as such workplaces are usually ill-equipped to capitalize their knowledge. Several projects have being carried out in some enterprises and industries to transfer senior competencies to junior collaborators by designing training plans where seniors train junior collaborators. MOCODIS aims at automating part of the training system, and use it as a complement to existing transfer methods.

Knowledge transmission from elder to younger generations constitutes a long tradition and can highly benefit to the transmission of skills and competencies when integrating new employees in companies.

Moreover, tutoring appears as naturally pertinent for employees with experience by offering them a most prominent diversification path in the second half of their careers, as well as for businesses by proposing better dynamics for their work pyramid.

Different studies, surveys and European reports all converge: "the know-how of older workers makes them an invaluable resource for employers ${ }^{3}$ and "the skills and experience of older workers are recognized as beneficial"4.

\footnotetext{
${ }^{3}$ http://eur-

lex.europa.eu/LexUriServ/LexUriServ.do?uri=COM:2004:0146:FIN:E $\mathrm{N}:$ PDF, p. 8

4

http://www.eurofound.europa.eu/ewco/reports/TN0407TR01/TN0407T R01.pdf, p.13
} 


\section{SHORT PAPER \\ Mobile Collection AND DisSEMINATION OF SENIORS' SKILls}

Nevertheless, the issue concerning senior employees is often considered as a problem more than part of a solution. MOCODIS offers a change of perspective.

MOCODIS offers a pedagogical tool based on a mobile ICT solution which addresses mainly two topics:

4. Considering the expertise of senior workers as valuable, valid and acute for the company, institution: collecting senior workers' competencies before they leave their job will help organizations capitalize on skills gradually developed through experience (such as in firms, manufacturing, production, analysis, etc.)

5. Offering senior expertise to junior workers, providing them with a mobile-based system: Enterprises, associations or NGOs widely offer their collaborators mobile devices to sustain their working efforts; seniors today are more accustomed to ICT based communication tools. Smartphones are currently used everywhere $^{5}$. Seniors employees are increasingly used to dealing with videos, participating in distant meetings using a webcam etc. Mobile devices are now easy to use and can produce good quality resources.

\section{MOCODIS DESCRIPTION}

The Mocodis system offers functionalities to :

- assist senior workers in the capture of their skills when and where they express the need for it,

- automatically create micro course capsules related to junior workers' web search,

- automatically adapt micro course capsules to juniors' needs thanks to a collaborative ranking system.

\section{A. In practice}

With their mobiles, seniors, acting as knowledge producers, film a tangible production (i.e. : how to perform a comfortable perfusion in a medical context, how to set up a performing electrical cabinet, how to welcome customers, etc.) and explain (audio capture) in what way this production is efficient, giving real advice on how to optimize the process etc.). When knowledge remains theoretical, audio flow or text based documents only are used.

Subsequently, this production is sent to the LMS addon. The system will automatically analyze the resource using speech-to-text and text-analysis algorithms to index it.

At the other end, knowledge consumers (trainees, junior employees) can seek knowledge by browsing a web-based research tool, and learn by imitation.

The Mocodis system associates indexed knowledge of the same kind and creates on the fly micro training capsules combining resources uploaded by seniors at the very moment the final user asks for it. A micro course lasts 5 minutes maximum and can be played again.

At the end of the process, juniors can rate the micro course, thus demonstrating how this mix of knowledge was useful to them. The resource will be ranked (the most useful knowledge, the most straight forward, etc.) by users and the system engine will prioritize this resource combination for the forthcoming similar request.

5 "95\% - "downtime"; $82 \%$ - at work; $81 \%$ - shopping; $80 \%$ - at home; $65 \%$ - commuting to work. Source: Questus » source :

http://www.smartphonemedia.co.uk/facts and figures.html
All add-on information flow can be monitored via a mobile device (web), which enables an "on spot" use at the very moment when situations occur or needs are expressed.

\section{TECHNICAL OVERVIEW}

Mocodis open source system can operate as a standalone module or be integrated into a SCORM compatible LMS.

The system offers two modules :

\section{A. Administration side}

DHR department adds topics and assigns seniors to it. Volunteer seniors then capture knowledge, upload it and tag it so the system can manage data to create the course capsule. The senior contributor also can modify, delete his own resources, e.i. whether a more suitable resource than a previously uploaded one should be taken into account by the system.

Mocodis accepts 3 types of resources : document, audio and video. All standard formats are supported. The content of each resource will be extracted and re-written for audio and video files. Those texts will then be processed by the indexation engine. Eventually, all files will be converted into different formats, in order to achieve an optimal reading, whether it be on a mobile platform or a desktop.

Text processing represents a heavy work load and is time-consuming, especially when a large number of resources need to be processed. Therefore, a follow-up module is provided so that the seniors can check on how the processing progresses.

\section{B. Client side}

Junior consumers can search through Mocodis using a full text search system. Mocodis will browse the available resources and match the search with a corresponding video, audio and text resource.

Mocodis' search is not limited to the words entered by the user, but also uses synonyms or words in a similar lexical range, in order to increase the possibilities to find a pertinent resource.

The junior visualizes a resource and ranks it.

The system also provides a history log, so that the junior can access his previous searches.

\section{WIDENED APPLICATION}

The Mocodis system can be submitted to the collaborators of a firm, a hospital institution, a NGO or any other organization involving human resources and competencies to be transferred. Even though the concept was designed to support knowledge transmission between seniors and juniors, the system can welcome any type of knowledge to be transferred, originating from an institutional source, top down.

Thus, it is possible for a firm department to produce short sequences on a topic specific to the concerned department (security measures, user instructions, dress code, tutorials dealing with particular characteristics of the software used in a company, tips and hints, welcoming new customers, etc.). The collaborators can consume the documents created for them, whenever needed, on their favourite media or the most pertinent support available. 


\section{SHORT PAPER}

\section{Mobile Collection AND DisSEMINATION OF SENIORS' SKILlS}

From the perspective of micro MOOCS (micro Massive Open Online Courses), Mocodis also represents a pertinent approach. Instead of developing long and complex courses, it becomes possible to develop a myriad of specific resources, designed to be cleverly combined, in order to produce the knowledge transfer aimed at, and thus achieving the reinforcement of a competence in action. Therefore, the University of Applied Sciences Western Switzerland (HES-SO) had decided to integrate Mocodis in its training scheme for its professors and administrative personnel. The notions to be transferred are designed by specialists and delivered on demand to the concerned personnel via the Mocodis system, embedded in the LMS Moodle used by this institution.

\section{CONCLUSION}

Collaborators reaching the end of their participation in the firm's professional activities, often wish to share their competencies, but rarely have the opportunity to do it formally. Recognizing the value they represent for the firm, is part of the elements to implement in order to further motivate collaborators who may need to work for a longer period in their life. (1). Moreover, competence transfer from senior to junior, shortens the learning period for the junior and enables the collaborators to be more efficient more rapidly, which has a favorable effect on competitiveness.

Using Mocodis top down, maintains the level of the collaborators' competencies, without requiring costly resources (time, logistics) or heavy workloads for their implementation. It fits well with the changes in society (speed, multitasking) and suits perfectly the collaborators' profiles as "digital natives". The manager wishing to consider this type of profile will highly benefit from the "working and cooperation to enable collective emulation" (le chevallier, 2014), by encouraging independence and personal involvement from this type of collaborator.
Thus, a process of win-win will fall into place to which Mocodis wishes to participate.

\section{REFERENCES}

[1] K. Billy. Des actions en faveur de l'employabilité des seniors. Info Flash, nº 679 pp. 13-18, 2006.

[2] https://asso.univ-lyon2.fr/apiraf/IMG/pdf/Apiraf seniors.pdf .

[3] P. Cappelli, B. Novelli. Managing the Older Worker: How to Prepare for the New Organizational Order. Harvard Business Review Press, 2010.

[4] European Commission. Increasing the employment of Older Workers and Delaying the Exit from the Labour Market. COM 146 final, Brussels, 2004.

[5] I. E. Kotowska. Older Workers in the Labour Market and Retirement Policies. European, 2003.

[6] A. Lechevallier. Le management des Digital Natives. ICD - International Business School Toulouse - Master II spécialisé Web Marketing \& E Business, 2014.

[7] G. Le Nagard. Les entreprises ne pourront pas se passer des seniors. In Entreprise \& carrières, ${ }^{\circ} 721$, pp.30-31, 15/06/2004.

[8] P. Taylor. A New Deal for older workers? The employment situation for older workers in the United Kingdom. In Maltby T., 2003.

[9] B. De Vroom and M-L. Mirabille. Ageing and Transition to Retirement. A Comparative Analysis of European Welfare States. Ashgate, Aldershot, 2004.

[10] S. Volkoff, C. Delgoulet and M. Millanvoye. Les capacités des travailleurs vieillissants : une approche conditionnelle. Futuribles $\mathrm{n}^{\circ} 314$, pp. 5-23, 2005.

\section{AUTHORS}

Anne-Dominique Salamin and Leyun Xia are with the HES-SO/Institute of Information Systems, Sierre, Switzerland.

This article is an extended and modified version of a paper presented at the International Conference on E-learning in the Workplace 2015 (ICELW'15), held in June 2015, at Columbia University in New York, NY, USA. Submitted 04 July 2015. Published as resubmitted by the authors 30 August 2015. 